\title{
The storied mind: A meta-narrative review exploring the capacity of stories to foster humanism in health care
}

\author{
Rachel Rose ${ }^{1}$, Saugata Chakraborty ${ }^{2}$, Ping Mason-Lai ${ }^{2}$, Willow Brocke ${ }^{3}$, Stacey A. Page ${ }^{4}$, David Cawthorpe ${ }^{* 5}$ \\ ${ }^{1}$ Department of Child and Youth Studies, Mount Royal University, Calgary, Canada \\ ${ }^{2}$ Engagement \& Patient Experience, Alberta Health Services, Canada \\ ${ }^{3}$ Brocke \& Associates Inc., Haskayne School of Business, Canada \\ ${ }^{4}$ Cumming School of Medicine, University of Calgary, Calgary, Canada \\ ${ }^{5}$ Faculty of Medicine, Departments of Psychiatry \& Community Health Sciences, Institute for Child \& Maternal Health, The \\ University of Calgary, Calgary, Canada
}

Received: October 7, 2015

DOI: $10.5430 /$ jha.v5n1p52
Accepted: November 8, 2015

Online Published: November 20, 2015

\begin{abstract}
Objective: Healthcare organizations are increasingly engaging the voice of patients and families through storytelling initiatives in hopes that this will yield compassionate and humanistic outcomes. To date, very little research is available that directly guides and justifies storytelling initiatives as a mechanism for promoting humanistic culture shifts in healthcare. This review aimed to uncover diverse research and evidence on how storytelling can be utilized to promote humanistic shifts in healthcare organizations.

Methods: A meta-narrative review and analysis was undertaken including qualitative, quantitative, theoretical, and conceptual papers. Searches were restricted to English Language journals, and no time frame restrictions were made. A literature assessment form was created to guide the review using a consistent taxonomy to appraise each paper. Analysis was done in two-stages: firstly, identifying emergent themes within each research discipline; secondly, comparing and contrasting themes from the different disciplines.

Results: A total of 115 papers were identified for review resulting from the literature review protocol. Eighty-three papers were included in the final review: 48 papers from Healthcare/Medicine combined, 28 from Business, 14 from Education, 5 from Organizational Development and 19 from Humanities (inclusive of Psychology and Communications). There were three key findings: 1) Storytelling promotes sense-making while also perpetuating bias; 2) Stories are uniquely primed to elicit empathy and compassion; 3) Story listening and how stories are interacted with by the listener are key considerations for organizations aiming to shift culture.

Conclusions: This review solidifies storytelling as a mechanism suited to furthering humanistic practices in healthcare while contributing new knowledge in support of developing policies, strategies and research initiatives that account for how stories are understood and the processes that encourage reflection and interaction by listeners.
\end{abstract}

Key Words: Humanism-in-healthcare, Organization change management, Patient experience, Meta-narrative review, Sensemaking, Storytelling

*Correspondence: David Cawthorpe; Email: cawthord@ucalgary.ca; Address: Faculty of Medicine, Departments of Psychiatry \& Community Health Sciences, Institute for Child \& Maternal Health, The University of Calgary, Calgary, Canada. 


\section{INTRODUCTION}

Being humanistic is broadly and generally defined as that which compassionately emulates the good in thought, action and deed, in the most socially Platonic sense. In recent decades, there has been a humanistic shift in healthcare toward understanding how patients experience their care as a means of better supporting their healing. ${ }^{[1-4]}$ Patient experience data, both quantitative and qualitative, are collected in many ways including a range of data from patient satisfaction and experience which includes stories, anecdotes or narratives spanning the duration of patient care. At the point of care, healthcare providers consistently hear patient's stories and experiences allowing them to informally learn about how patients are experiencing their care. Stories are ubiquitous and intimately connected to human interaction. ${ }^{[5]}$ Evidence shows that when healthcare providers share information in the form of narratives or through stories of other patient experiences, it can impact and change patient behaviours and health outcomes in profound ways. ${ }^{[6]}$ This body of literature speaks to the potential impact of stories to promote behaviour changes. Nevertheless, a gap exists in knowledge about the theoretical and practical implications of how this plays out in terms of the impact of patient stories on institutional culture. Stories have the potential to evoke compassion, empathy, and inspiration, and, while difficult to measure and quantify in traditional ways ${ }^{[7-9]}$ healthcare may learn from their successes and approaches to synthesizing evidence. Health Services work to improve multiple dimensions of quality by hearing and understanding the stories of patients, families, leaders, and care providers. One aim of this review is to explore and synthesize evidence about how patient stories might be utilized to support the vision and values in health organizations: How can patient stories contribute to humanism in the current healthcare culture? The knowledge and evidence uncovered through the review will be used to develop education and strategies for change to support the uptake of evidence-based patient-centred practices leading to a more humanistic healthcare culture.

\section{Methods}

Recognizing the diverse landscape of storytelling and its inherent centrality in human communication, we used a meta-narrative analysis method to guide the literature review. This work was conducted in accordance with the RAMESES publication standards for meta-narrative reviews. ${ }^{[10]}$ The meta-narrative analysis followed a comprehensive process using rigorous methodological guidelines to synthesize the heterogeneous forms of evidence. ${ }^{[7-10]}$ We identified disciplines that have considered storytelling and worked with our librarian to identify databases for each area. The relevant traditions were initially considered to be Business, Health, Organizational Development, Humanities, EducaPublished by Sciedu Press tion, Indigenous Studies, and the Arts. As a result, Medline, PubMed, CINAHL, Ovid, The Permanente Journal, Science Direct, Forbes, Harvard Business Review, Business Source Complete, Academic Search Complete, ProQuest, EBSCO, FastCompany, SAGE publications, New Directions for Adult and Continuing Education, Qualitative Report, PsycINFO, ERIC and Google Scholar were searched. Search terms were: storytelling, storytelling and culture change, storytelling and patients, storytelling and types, storytelling and utility, narrative, narrative and culture change, narrative and patients, narrative and types, narrative and utility. Searches were restricted to English Language journals; no time frame restrictions were made. The use of storytelling as an effective change or influence mechanism is relatively new. Therefore, research studies of all designs (experimental and non-experimental) with this focus were considered to capture both breadth and depth of information. The study selection used the following inclusion criteria: 1) Storytelling has been used as interventions with the main purpose of uptake of a practice, strategy, or sharing information; 2) Empirical studies in which storytelling is a factor in outcomes at a process, economic, or healthcare level. This inclusion criterion in conjunction with our research questions proved to be useful guides during the iterative searching process.

We searched review methods from other meta-narrative reviews and created an assessment method combining and adapting a few to meet our specific context and needs. ${ }^{[11-13]}$ The form consisted of the following fields: 1) Is this paper relevant to our research questions and worthy of further consideration? 2) How does this paper fit into our taxonomy? 3) How does this paper address our appraisal questions? (see Table 1)

Table 2 describes the document flow process. The bibliography contains the list of included and excluded articles in addition to 7 papers referenced in respect to methods.

Similar proportions of each domain were represented in the total number of included references; however, most papers came from the Qualitative domain (see Table 3). Table 3 shows columns ranked from largest to smallest by Qualitative Type.

\section{RESUlts}

The resulting literature was first understood and conceptualized in a context dependent manner as identified by the themes emerging in the fields of Healthcare, Business, Organizational Development, Education, and Humanities. Each discipline conceptualized storytelling uniquely, offering insights and research relevant to providing a comprehensive view of storytelling as a mechanism for promoting a culture of humanism in healthcare. 
Table 1. Research phases

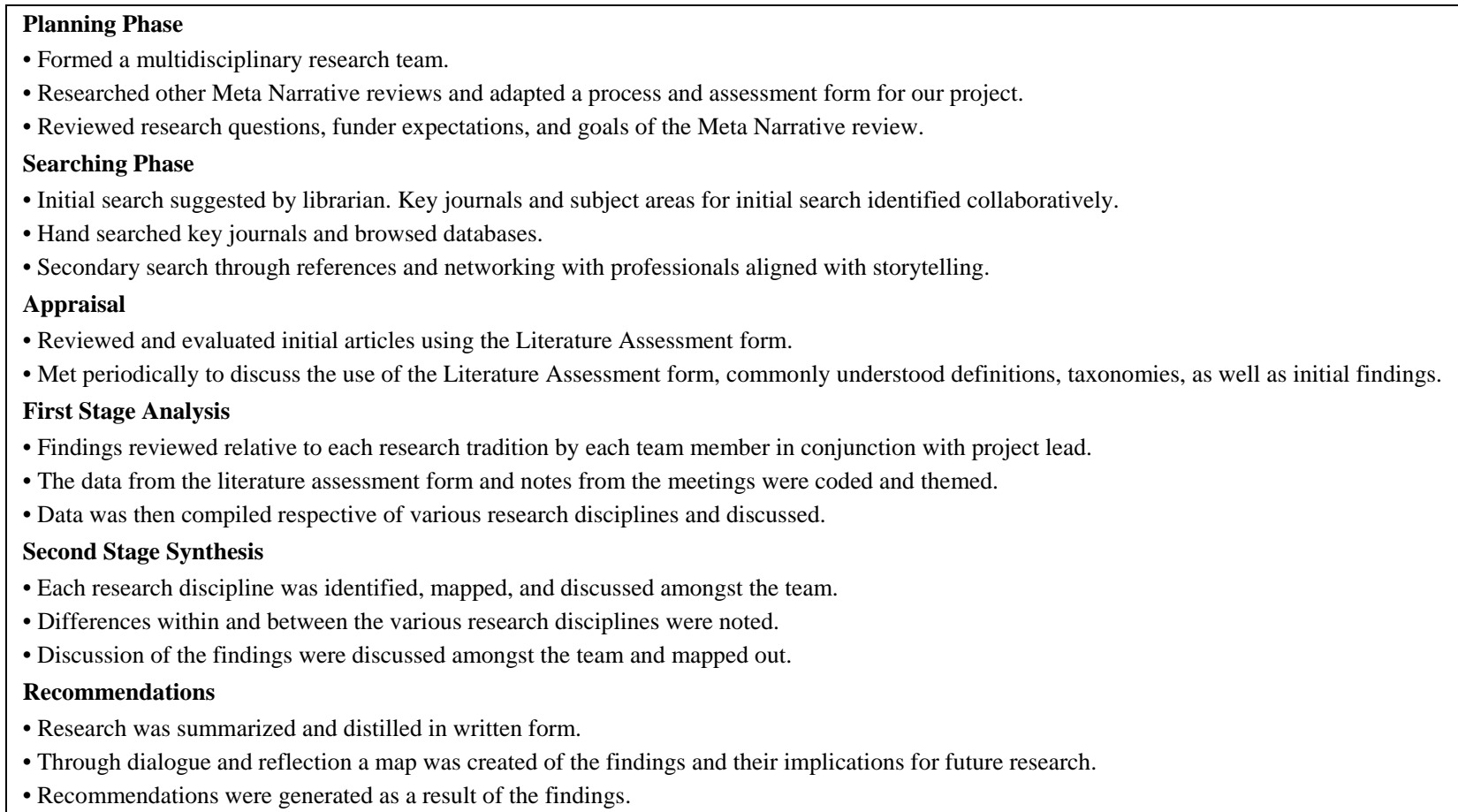

Table 2. Document flow diagram

Stage 1
An initial search was conducted using key words in the various databases. Throughout the process reviewing reference lists also identified articles.
Stage 2
Abstracts examined and studies were included if they met the following inclusion criteria: 1) Storytelling has been used as interventions with the main
purpose of uptake of a practice, strategy, or sharing information; 2) Empirical studies in which storytelling is a factor in determining the outcomes of
a process (e.g., as in economics of healthcare).
Stage 3
A total of 115 papers were identified for review resulting from the literature review protocol. There were 7 additional papers (general/unclassified)
that were cited in reference to search and review methods. Each of these papers is cited in the paper's body and appears in the reference section.
Stage 4
Each article was assigned to a team member for review. Each team member utilized the literature assessment form to help determine if the data or
information was ultimately relevant to our research questions. Eighty-three papers were included in the final review 48 papers from
Healthcare/Medicine combined, 28 from Business, 14 from Education, 5 from Organizational Development and 19 from Humanities (inclusive of
Psychology and Communications).

Table 3. Summary of article subject and type

\begin{tabular}{|c|c|c|c|c|c|c|c|c|}
\hline \multirow[b]{2}{*}{ Subject } & \multicolumn{8}{|c|}{ Type } \\
\hline & Theory/Conceptual & Qualitative & Quantitative & $\begin{array}{l}\text { Qualitative \& } \\
\text { Quantitative }\end{array}$ & Editorial & Other & $\begin{array}{l}\text { Total } \\
\text { included }\end{array}$ & $\begin{array}{l}\text { Total From } \\
\text { search }\end{array}$ \\
\hline Business & & 19 & 4 & 1 & & & 24 & 28 \\
\hline Health & 1 & 13 & 1 & & 3 & 1 & 19 & 27 \\
\hline Education & 2 & 8 & & 3 & & & 13 & 14 \\
\hline Organizational Development & & 5 & & & & & 5 & 5 \\
\hline Psychology & & 4 & & & & & 4 & 5 \\
\hline Medicine & 5 & 4 & 2 & & & 1 & 12 & 21 \\
\hline Humanities & 1 & 3 & & & & 1 & 5 & 14 \\
\hline Communications & 1 & & & & & & 1 & 1 \\
\hline Total & 10 & 56 & 7 & 4 & 3 & 3 & 83 & 115 \\
\hline
\end{tabular}


Research in healthcare indicated that storytelling was found to be used in healthcare in five ways: 1) to foster sensemaking and sense-giving; 2) to support the exchange of tacit learning and support knowledge translation; 3) to educate providers, patients and families; 4) to promote attributes such as empathy and compassion; 5) to facilitate cultural change and to enhance individual/healthcare provider behaviour. Each of these themes showcases storytelling as practice with historical significance in healthcare with use of storytelling as an engaging way to communicate and assist patients, families, and healthcare providers to make sense of the health journey. ${ }^{[14-16]}$ Story and narrative is often used interchangeably as synonyms, but regardless of the words the purpose within healthcare is consistent. Both are used to build a human connection, to create affiliation and authenticity with the storyteller and their audience. ${ }^{[17]}$ Sensemaking and sense-giving is specifically critical to patients who are managing life-threatening diseases and chronic conditions. ${ }^{[14,16,18-20]}$ The second theme of storytelling being used to promote the exchange of tacit learning and knowledge translation showcases how storytelling has been strategically used in healthcare. ${ }^{[21,22]}$ The third major theme was storytelling being used as a tool for educating both patients and healthcare providers, highlighting the range of educational uses for story, from health promotion to chronic disease management. ${ }^{[6]}$ The use of digital stories in a DVD format was an effective and far reaching medium used in promoting behavior changes. ${ }^{[23]}$ Storytelling is most prevalent within healthcare education to train and teach new generations of healthcare providers, including physicians ${ }^{[17,19]}$ to promote professional development and learning. ${ }^{[24-27]}$ The fourth major theme is the use of storytelling to promote attributes in listeners (e.g., empathy and compassion). ${ }^{[6,21,23,28,29]}$ In this example, the issue of the affect bias implicit in the creation and sharing of stories can have both practical as well as ethical implications impacting effective empathetic care. The final theme to emerge was the potential for stories to facilitate culture change in healthcare. Stories and storytelling have also been used to improve the quality of care ${ }^{[20,31-33]}$ and stories over statistics and numbers are much more compelling and can lead to policy and legislative improvements. ${ }^{[34,35]}$

The mechanisms for the sharing of stories in the articles reviewed include oral, digital, and printed resources (pamphlets). The addition of visual pictures enhanced the messages and assisted in education of patients and their families. Context and setting were also identified as important elements for the mode of storytelling with face-to-face, groupbased and situational circumstances (disease, culture, gender and age specific). The literature in healthcare and medicine reflects limited use of storytelling (or narrative) to promote

Published by Sciedu Press behavior or culture change; however, the articles reviewed cited storytelling as a mechanism or process for an intended outcome without convincingly demonstrable evidence of tangible changes to behavior or practice. Research in business literature provided a deep and nuanced portrait of storytelling showcasing the key attributes of storytelling as culture change, knowledge transmission, innovation, organizational leadership, and building brand loyalty in which oral storytelling is the most commonly used mechanism of sharing stories $^{[5,36-45]}$ followed by digital media such as social media, blogs, online interactive forums, and e-mail. ${ }^{[38,43,46,47]}$ In a variety of business contexts, storytelling was adopted as an ubiquitous tool to bring about a particular change, demonstrating its effectiveness. ${ }^{[38,45,48]}$ The attributes of storytelling identified across the business literature are as follows: 1) It has an universal appeal to culturally diverse audiences with varied interests, perspectives, and learning styles; ${ }^{[38]} 2$ ) It is valued as an integral part of the human experience $^{[45]}$ with the inherent capacity to generate emotional connection and therefore a natural platform for transmission of knowledge which sticks; ${ }^{[49]} 3$ ) It provides for a flexible framework to disseminate information, to share tacit knowledge, to coach and train; ${ }^{[48,50]}$ and 4) when told in an engaging manner, taking into account the relevance to the audience and proper emotional content, it can act as a powerful enabler to convey complex and multidimensional ideas, information and insight for facilitation of group norms, values, collaborative understanding and work, generating consensus and new ideas. ${ }^{[5,37-40,47,51]}$ Evidence shows that such stories have led to engendering trust, goodwill and internal loyalty among the employees, higher employee engagement and effective implementation of the organization's strategic goals resulting in enhanced the reputation of the company. ${ }^{[38]}$

A major theme appearing within the business literature is the application of storytelling as a tool for leaders to effectively obtain "buy-in" and communicate their vision and authentically share their life story and knowledge with employees. ${ }^{[44,45,48,52]}$ There are studies that show how storytelling is being used by organizations to elicit tacit knowledge from retiring subject matter experts and overcome current challenges. ${ }^{[41,42,53,54]}$ Storytelling has been used as an effective marketing strategy for building brand loyalty and value with consumers. ${ }^{[43,46,55,56]}$ Business literature reviewed reflects a more purposeful and strategic use of storytelling to achieve a culture change through structured pre-defined goals and objectives and is replete with evidence of tangible outcomes.

Organizational development is an interdisciplinary undertaking that aims to better understand how organizations and the individuals in them can best achieve strategic objectives such as efficiency and effectiveness and an organization's ability 
to respond adaptively to change (e.g., new technology, redefining roles and responsibilities). ${ }^{[57-60]}$ In Organizational Development the use of stories as a tool to achieve organizational objectives emerged in two key themes: 1) the role of stories in sense-making and identity for individuals and groups within organizations, and 2) that new stories are subject to the pressures and constraints of existing narratives creating a dynamic and interplay that impacts how it is heard and received by individuals and the organization at large. ${ }^{[57-59,61,62]}$

Educational research conceptualizes storytelling as a foundational form of inquiry integral to learning and understanding complexity. A review of educational research yields five major themes: 1) discussion around the differences in function between narrative and storytelling; 2) storytelling as sensemaking; 3) storytelling as a diverse educational tool; 4) tacit learning through storytelling; 5) story providing voice and agency. The findings suggest that storytelling is a useful tool in education as well as supporting inquiry and understanding in traditionally marginalized areas. ${ }^{[28,63-69]}$ Storytelling is seen as a mechanism for sense and meaning making in education, ${ }^{[28,67,70]}$ wherein listeners recognizing their position in relation to a story. ${ }^{[28,66,67,71-76]}$ Storytelling has also been conceptualized as a key mechanism for providing voice, or agency, to those who are typically marginalized or not heard or understood within educational environments. ${ }^{[28,64,67,68,71,72,74]}$

The Humanities literature revealed five major themes: 1) the therapeutic aspect of story; 2) sense-making and story; 3) storytelling as a potential counter to the normative; 4) the interplay between the storyteller and listener; and 5) storytelling as a potential to promote culture change. ${ }^{[27,77-79]}$ Storytelling promotes humanism through interplay between the teller and the listener with benefits for the listener or receiver of the story. ${ }^{[79]}$ The second theme conceptualized storytelling as a communication tool promoting sense-making amidst increasingly complex human interactions such as culture, organizations, and social movements. ${ }^{[80-82]}$ Another way that storytelling promotes sense-making is through the pairing of stories and statistics. Statistical evidence may help to tell an effective story ${ }^{[83]}$ but it is also key to the decision about whether use of a specific story should even be considered, ${ }^{[84]}$ such as to coax imaginations or challenge commonly held beliefs. The fourth theme characterizes the interplay between how the story is told and how the story is received. ${ }^{[80,85]}$ One's own bias and filter has a significant impact on how one interprets and makes sense of a story. ${ }^{[86]}$ The final theme cited how storytelling could be used to promote culture change. ${ }^{[85,87]}$ The findings of this research showed that story based interventions were more effective than information based ones for changing attitudes. For example, creative or fictional storytelling has a unique ability to support attitude and belief changes. ${ }^{[88,89]}$

\section{SUMMARY OF FINDINGS}

Synthesizing the findings from each research discipline, a number of key themes emerge. There were three key findings that were relevant to the inquiry: 1) sense-making through storytelling; 2) the ability of stories to elicit empathy and compassion; and 3) complexity in how stories are heard or listened to. Understanding each of the themes in relation to each other uncovers new insights and directions for future research pertaining to storytelling as a tool of culture change promoting humanism in healthcare.

One of the key attributes of storytelling that makes it an effective tool for fostering a humanistic culture shift in healthcare is its unique ability to facilitate sense-making. Four key themes emerged suggesting that the sense-making attributes of storytelling support humanistic culture change in healthcare: 1) story captures and retains emotions; 2) tacit learning and knowledge translation are aided through story; 3 ) story helps the complex become simple; 4) story helps foster inquiry and understanding with ethical implications relevant to identity building and change.

Storytelling has a unique ability to retain and capture emotion, and is especially suited to humanism, which by virtue is emotional. Healthcare, education, and business all underscore emotional sense-making through story. Stories create a space for emotional content that may otherwise be missed, excluded, or lost in other forms of communication. Storytelling was suggested as a useful tool in supporting tacit learning and knowledge translation. In healthcare, there has been success in utilizing story to help patients cope with emotions related to their health condition. However, capitalizing on stories from staff that already have a known capacity to provide high quality humanistic care, is an underexplored avenue. How might healthcare benefit from sharing patient, family, and healthcare provider stories as a means of drawing out and decoding the complexities behind providing humanistic care?

Another dimension of sensemaking in storytelling is its ability to make what is complex more easily understood. In $\mathrm{Hu}-$ manities, Business, Healthcare, and Education it was argued that society, organizations, cultural diversity, and history are all becoming more complicated in modern times, requiring individuals to utilize tools that allow for complexity to be retained and understood, rather than risk more reductive means which may result in oversimplifications. Stories are also understood as a form of inquiry, a way of understanding what 
is complex, such as emotions as well as unnamed or codified knowledge. In this way, the stories can become both a tool to promote sense-making, as well as a method of sense-making. Stories represent an engine that characterizes and reinforces an organizational culture resulting in bias. Organizational and individual biases are fuelled by stories; however, they may also be undone through stories.

In the case of healthcare, storytelling can be used as a form of inquiry to capture and name the barriers to humanistic healthcare while also stimulating new stories that counter current bias and challenge traditional modes of oppression. How might the systematic introduction of patient, family, and healthcare provider stories contribute to stimulating the imaginations of those operating under the potential blinders of organizational bias? Storytelling can be utilized as a form of inquiry to uncover the complexity of how bias may be countering humanistic care practices while also uncovering stories where changes and shifts towards more humanistic care have been achieved successfully.

From an ethical perspective, stories include and exclude information in order to make sense to both teller and listener, and by nature, represent the very essence of bias. Narrative bias contributes to the identity and stability of an organization. Narratives are not introduced into a vacuum; each individual or group listening to an organizational narrative listens to it from within a complex network of pre-existing stories. Narratives can powerfully shape organizational dynamics in intended or unintended ways which may improve or impede organizational flexibility. The structure of narrative creates networks of self-reinforcing information while excluding non-reinforcing information and points to the issue of listener bias as a key factor in understanding how stories may impact organizational goals.

The ability of a story to retain and hold values, emotions, and complex information through its unique sense-making feature accounts for its longstanding presence in healthcare as a tool for promoting empathy and compassion. As healthcare organizations continue to grow and expand upon humanistic practices, much can be learned from the insights garnered from the various research disciplines about how story can promote and encourage empathetic and compassionate care There were four key themes uncovered proving significant to employing storytelling in healthcare for empathetic and compassionate means: 1) the therapeutic impacts for the storyteller; 2) the successful use of story in the one-on-one transmission of empathy and compassion; 3) the long standing tradition of using story in medical education to promote empathy and compassion as well as studies that have expanded this practice to impact communities; 4) the discourse surrounding the use of creative storytelling and perceived authenticity. Each of these insights suggests that there are new and imaginative ways that stories could be utilized to promote empathy and compassion in healthcare.

One of the main findings in the literature demonstrates that when a person shares their own personal story, there are therapeutic elements for both storyteller and for the listener. Not only is storytelling therapeutic for the person sharing their story but a wide range of evidence shows that the person hearing the story experiences an increase in empathy and compassion towards the storyteller. The reciprocal benefits of storytelling suggest that as a person shares their own story that they have the potential to benefit therapeutically, while the story listener experiences increased empathy and compassion towards the storyteller, implying that storytelling has versatility in multiple contexts for fostering wide ranging humanistic impacts, thereby establishing credibility for expanding this practice in such a way that stories can target groups of people or entire organizations, not just an individual, to promote a more compassionate healthcare system.

For healthcare to focus on the more humanistic aspects of its enterprise, both patients and care providers voices have the potential to become agents of change supporting healing and increased connection between healthcare providers as well as patients and families. Leadership is a key element in creating world-class humanistic healthcare organizations and every leader necessarily leads with a story. The success of storytelling in promoting empathy and compassion suggests that this is a useful tool in supporting humanistic care. Healthcare leaders must examine how storytelling can be used in promoting new innovation.

The most common theme throughout each of the fields was the significance of how a story is heard and understood by the listeners. Each field placed different emphasis on the importance of this, highlighting the relevance of listening, and showcasing how various contexts and applications are vulnerable. Two major themes emerged across the literature on this topic: 1) an emphasis on the process of storytelling over the content; and 2) a focus on the dynamic interplay between storyteller and listener. These findings suggest that specific emphasis on how a story is heard must be part of strategies that aim to use storytelling as tools of change. Organizational development placed particular emphasis on this identifying the presence of a complex network of existing organizational stories about who they are, what they do, and why they do it as a key factor in how change initiatives unfold. When a new story is introduced without understanding it fully, or weaving it into the existing stories, a risk is present, in that, resistance to the current story is either strengthened or a counter story 
emerges in order to reduce the of loss of existing identity. Healthcare has explored the interplay between story content and process by marking the ability of stories to enhance and foster relationship between care providers and patients.

The second major theme identified across the literature is the potential for stories to become a dynamic interplay between storyteller and listener. Story has been successfully used as a starting point to spur collaboration, engagement, and reflective practice. Utilizing storytelling as a tool to begin deepening the relationship between teller and listener is a distinctly different approach than seeing story as an end. In Education, storytelling was conceptualized as a tool utilized to promote collaboration through communities of practice. In Business, storytelling is used in similar ways, as a device to begin fostering collaboration or innovation with group storytelling proving to be a successful tool in promoting collaboration and innovation.

The literature reviewed in this paper makes it clear that stories can be powerful shapers of our perceptions, as individuals as well as in groups and organizations. It is also clear that harnessing the power of stories in order to procure a specific outcome is a complex and multilayered task, requiring consideration of issues such as ethics, adaptability, context, bias, fragmentation, and identity. How stories are heard and interpreted is a traditionally overlooked area of work and where storytelling initiatives often go wrong. If organizations don't account for how the story is heard, they simply assume that the story will have the intended impact. Storytelling for the purpose of human change may work best if it is an exchange of stories that goes both ways to allow for a shift in thinking to occur.

\section{Strengths, limitations and future research directions}

The inherent complexity behind how story is defined and conceptualized across the literature was challenging. This might impact the overall strength of our findings as encompasses a wide variety of contexts and uses which may or may not be generalizable to healthcare settings. The main strength of our study is that it appears to be the first attempt to conceptualize storytelling as a mechanism for promoting a humanistic culture in healthcare. The implications of our findings provide insights for healthcare organizations to begin implementing in policy and practice, which will ideally lead to specific research focused on mechanism.

\section{Conclusions}

Healthcare organizations are increasingly engaging the voice of patients and families through storytelling initiatives in hopes that this will yield compassionate and humanistic outcomes. Yet, very little research or data is available to guide storytelling initiatives, as mechanisms promoting humanistic shifts in healthcare culture. Our findings suggest that storytelling is suited to help healthcare providers make sense of the increasing complex workplace and care interactions.

Stories are the basis for how culture is formed and perpetuated in organizations. Storytelling is positioned to help decode, honour, include, and foster emotions, such as empathy and compassion between patients, families, and care providers. The flexible and versatile framework of storytelling is effective in supporting healthcare organizations use of imaginative and new ways for supporting development of a humanistic culture through formal introduction and use in health education curriculum, organizational and administrative relationships, within and between health care provider disciplines (e.g., nursing and medicine) and especially between care-providers and patients. This review solidifies storytelling as a mechanism underpinning humanistic practices in healthcare while contributing new knowledge in support of developing policies, strategies, and research initiatives that account for how stories are heard, and the processes that encourage reflection and interaction by listeners. Healthcare must acknowledge existing stories and biases for better or for worse to give rise to and perpetuate organizational norms.

\section{ACKNOWLEDGEMENTS}

This project was made possible with a grant from the Arnold P. Gold Foundation.

\section{REFERENCES}

[1] Doyle C, Lennox L, Bell D. A systematic review of evidence on the links between patient experience and clinical safety and effectiveness BMJ Open. 2013; 3(1). http://dx.doi .org/10.1136/bmjopen $-2012-001570$

[2] Luxford K, Safran DG, Delbanco T. Promoting patient-centered care: A qualitative study of facilitators and barriers in healthcare organizations with a reputation for improving the patient experience. International Journal for Quality in Health Care. 2011; 23(5): 510-
515. PMid: 21586433. http://dx.doi.org/10.1093/intqhc/ mzr024

[3] Price RA, Elliott MN, Zaslavsky AM, et al. Examining the role of patient experience surveys in measuring health care quality. Medical Care Research and Review. 2014; 71(5): 522-554. PMid: 25027409. http://dx.doi.org/10.1177/1077558714541480

[4] Tsianakas V, Robert G, Maben J, et al. Implementing patientcentred cancer care: using experience-based co-design to improve patient experience in breast and lung cancer services. Support- 
ive care in cancer. 2012; 20(11): 2639-2647. PMid: 22544223. http://dx.doi.org/10.1007/s00520-012-1470-3

[5] Sole D, Wilson DG. Storytelling in organizations: The power and traps of using stories to share knowledge in organizations. LILA, Harvard Graduate School of Education. 2002.

[6] Fix GM, Houston TK, Bake AM, et al. A novel process for integrating patient stories into patient education interventions: Incorporating lessons from theater arts. Patient Education and Counselling. 2012; 88(3): 455-459. PMid: 22770814. http://dx.doi .org/10. 1016 $/ j$.pec. 2012.06.012

[7] Brown AD, Gabriel Y, Gherardi S. Storytelling and change: An unfolding story. Organization. 2009; 16(3): 323-333. http://dx.doi . org $/ 10.1177 / 1350508409102298$

[8] Hedgren Sandberg S, Johansson J, Åström E. If Everyone Knew What Everyone Knows, Everyone Would Know More-How Organisational Storytelling Can Be Used to Manage Tacit Knowledge. Jonkoping International Business School: Unpublished Thesis; 2012.

[9] Scott SD, Brett-MacLean P, Archibald M, et al. Protocol for a systematic review of the use of narrative storytelling and visualarts-based approaches as knowledge translation tools in healthcare. Systemic Reviews. 2013; 2(1): 19. PMid: 23514237. http: //dx.doi.org/10.1186/2046-4053-2-19

[10] Woodside AG. Brand-consumer storytelling theory and research: Introduction to a Psychology \& Marketing special issue. Psychology \& Marketing. 2010; 27(6): 531-540. http://dx.doi.org/10.1002 /mar. 20342

[11] Cooper H, Charlton K, Valentine JC, et al. Making the most of summer school: A meta-analytic and narrative review. Monographs of the society for research in child development. 2000; 127.

[12] Greenhalgh T, Robert G, Macfarlane F, et al. Storylines of research in diffusion of innovation: A meta-narrative approach to systematic review. Social Science and Medicine. 2005; 61(2): 417-430. PMid: 15893056. http://dx.doi.org/10.1016/j. socscimed. 2004 . 12.001

[13] Potts HWW, Keen J, Denby T, et al. Towards a better understanding of delivering e-health systems: a systematic review using the metanarrative method and two case studies. NIHR Service Delivery and Organisation programme. 2011.

[14] Evans M, Shaw A, Sharp D. Integrity of patients' stories: 'Meanmaking' through narrative in supportive cancer care. European Journal of Integrative Medicine. 2012; 4(1): e11-18. http://dx.doi.o $\mathrm{rg} / 10.1016 / \mathrm{j}$. eujim.2011.12.005

[15] Haigh C, Hardy P. Tell me a story - a conceptual exploration of storytelling in healthcare education, Nurse Education Today. 2011; 31(4): 408-411. PMid: 20810195. http://dx.doi.org/10.1016 $/ j$. nedt. 2010.08.001

[16] Yoder-Wise PS, Kowalski K. The power of storytelling. Nursing outlook. 2003; 51(1): 37-42. PMid: 12595827. http://dx.doi.org $/ 10.1067 / \mathrm{mno} .2003 .2$

[17] Charon R. What to do with stories: The sciences of narrative medicine. Canadian Family Physician. 2007; 53(8): 1265-1267. PMid: 17872831

[18] Kear TM. The use of narrative analysis to study transformative learning in associate degree nursing students: a focus on the methodology. Teaching and Learning in Nursing. 2012; 7(1): 32-35. http: //dx.doi.org/10.1016/j.teln.2011.07.003

[19] Sandelowski M. We are the Stories we Tell: Narrative Knowing in Nursing Practice. Journal of Holistic Nursing. 1994; 12(1): 2333. PMid: 7806848. http://dx.doi.org/10.1177/089801019 401200105

[20] Clarke A, Jane Hanson E, Ross H. Seeing the person behind the patient: enhancing the care of older people using a biographical approach. Journal of clinical Nursing. 2003; 12(5): 697-706. PMid: 12919216. http://dx.doi.org/10.1046/j.1365-2702.2003 $.00784 . x$

[21] Hartling L, Scott S, Pandya R, et al. Storytelling as a communication tool for health consumers: development of an intervention for parents of children with croup. Stories to communicate health information. BMC Pediiatrics. 2010; 10(1): 64. PMid: 20813044. http://dx.doi.org/10.1186/1471-2431-10-64

[22] Larkey LK, Lopez AM, Minnal A, et al. Storytelling for Promoting Colorectal Cancer Screening Among Underserved Latina Women: A randomized pilot study. Cancer Control Journal of the Moffitt Cancer Center. 2009; 16(1): 79. PMid: 19078934.

[23] George DR, Stuckey HL, Whitehead MM. How a creative storytelling intervention can improve medical student attitude towards persons with dementia: A mixed methods study. Dementia. 2014; 13(3): 318 329. PMid: 24770946. http://dx.doi.org/10.1177/1471301 212468732

[24] Christiansen A. Storytelling and professional learning: A phenomenographic study of students' experience of patient digital stories in nurse education. Nurse Education Today. 2011; 31(3): 289-29. PMid: 21074909. http://dx.doi.org/10.1016/j.nedt. 2010 .10 .006

[25] Crookes K, Crookes PA, Walsh K. Meaningful and engaging teaching techniques for student nurses: a literature review. Nurse education in practice. 2013; 13(4): 239-243. PMid: 23683818. http: //dx.doi.org/10.1016/j.nepr.2013.04.008

[26] Moon J, Fowler J. 'There is a story to be told...'; A framework for the conception of story in higher education and professional development. Nurse education today. 2008; 28(2): 232-239. PMid: 17583389. http://dx.doi.org/10.1016/j.nedt.2007.05.001

[27] Hunter LP, Hunter LA. Storytelling as an Educational Strategy for Midwifery Students. Journal of Midwifery and Women's Health. 2006; 51(4): 273-278. PMid: 16814222. http://dx.doi.org/10. 1016/j . jmwh.2005.12.004

[28] Clark MC. Narrative learning: Its contours and its possibilities. New directions for adult and continuing education. 2010; 126. http://dx.doi.org/10.1002/ace.367

[29] Mishler E. Patient Stories, narratives of resistance and the ethics of human care; al la recherce de temps perdu. Health (London). 2005; 9: 431-450. PMid: 16144787. http://dx.doi.org/10.1177/1 363459305056412

[30] Ferguson LM, Ward H, Card S, et al. Putting the 'patient' back into patient-centred care: An education perspective. Nurse education in practice. 2013; 13(4): 283-287. PMid: 23602696. http: //dx.doi.org/10.1016/j.nepr.2013.03.016

[31] Gullick J, Shimadry B. Using patient stories to improve quality of care. Nursing Times. 2008; 104(10): 33-34.

[32] Robert G, Waite R, Cornwell J, et al. Understanding and improving patient experience: A national survey of training courses provided by higher education providers and healthcare organizations in England. Nurse Education Today. 2012; 34(1): 112-120. PMid: 23154150. http://dx.doi.org/10.1016/j.nedt.2012.10.012

[33] Wilcock P, Stewart Brown GC, Bateson J, et al. Using patient stories to inspire quality improvement within the NHS Modernization Agency collaborative programmes. Journal of Clinical Nursing. 2003; 12(3): 422-430. PMid: 12709117. http://dx.doi.org/10.1046 $/ j .1365-2702.2003 .00780 . x$

[34] Newman TB. The power of stories over statistics. British Medical Journal. 2003; 327(7429): 1424. PMid: 14684635. http: //dx.doi.org/10.1136/bmj.327.7429.1424

[35] Cass A, Lowell A, Christie M, et al. Sharing the true stories: Improving communication between Aboriginal patients and healthcare 
workers. Medical Journal Australia. 2002; 176(10): 466-471. PMid: 12065009 .

[36] Bowman G, MacKay RB, Masrani S, et al. Storytelling and the scenario process: Understanding success and failure. Technological Forecasting and Social Change. 2013; 80(4): 735-748. http: //dx.doi.org/10.1016/j.techfore.2012.04.009

[37] Carminatti N, Borges MR, Gomes JO. Analyzing approaches to collective knowledge recall. Computing and Informatics. 2006; 25(6): 547-570.

[38] Gill R. Corporate storytelling as an effective internal public relations strategy. International Business and Management. 2011; 3(1): 17-25

[39] Gorry GA, Westbrook RA. Can you hear me now? Learning from customer stories. Business horizons. 2011; 54(6): 575-584. http://dx.doi.org/10.1016/j.bushor.2011.08.002

[40] Kahan S. The power of storytelling to jumpstart collaboration. Journal for Quality and Participation. 2006; 29(1): 23.

[41] Lelic S. Fuel your imagination-KM and the art of storytelling. Knowledge Management. 2001; 20: 9.

[42] Mantere S, Aula P, Schild H, et al. Narrative attributions of entrepreneurial failure. Journal of Business Venturing. 2013; 28(4): 459473. http://dx.doi.org/10.1016/j.jbusvent.2012.12.00 1

[43] Mora P, Livat F. Does storytelling add value to fine Bordeaux wines? Wine Economics and Policy. 2013; 2(1): 3-10. http://dx.doi.o $\mathrm{rg} / 10.1016 / \mathrm{j}$. wep. 2013.01.001

[44] Sparrowe RT. Authentic leadership and the narrative self. The Leadership Quarterly. 2005; 16(3): 419-439. http://dx.doi.org/10. 1016/j.leaqua. 2005.03.004

[45] Weischer AE, Weibler J, Petersen M. To thine own self be true: The effects of enactment and life storytelling on perceived leader authenticity. The Leadership Quarterly. 2013; 24(4): 477-495. http: //dx.doi.org/10.1016/j.leaqua.2013.03.003

[46] Chiu H, Hsieh Y, Kuo Y. How to align your brand stories with your products. Journal of Retailing. 2012; 88(2): 262-275. http: //dx.doi.org/10.1016/j.jretai.2012.02.001

[47] Escalfoni R, Braganholo V, Borges M. Applying group storytelling to capture innovation features. Computer Supported Cooperative Work in Design. CSCWD 2009. $13^{\text {th }}$ International Conference on IEEE; 2009. http://dx.doi.org/10.1109/cscwd. 2009.4968060

[48] Mládková L. Leadership and Storytelling. Procedia-Social and Behavioral Sciences. 2013; 75: 83-90. http://dx.doi.org/10.10 $16 /$ j.sbspro.2013.04.010

[49] Szulanski G. Exploring internal stickiness: Impediments to the transfer of best practice within the firm. Strategic management journal. 1996; 17(S2): 27-43. http://dx.doi .org/10.1002/smj . 42501 71105

[50] Dowling GR. Communicating corporate reputation through stories. California Management Review. 2006; 49(1): 82. http://dx.doi .org/10.2307/41166372

[51] McWhinney W, Batista J. How remythologizing can revitalize organizations. Organizational Dynamics. 1988; 17(2): 46-58. http: //dx.doi .org/10.1016/0090-2616(88)90018-6

[52] Ready DA. How storytelling builds next generation leaders. MIT Sloan Management Review. 2002.

[53] Whyte G, Classen S. Using storytelling to elicit tacit knowledge from SMEs. Journal of Knowledge Management. 2012; 16(6): 950-962. http://dx.doi.org/10.1108/13673271211276218

[54] De LDW, Thomas D. Better practices for retaining organizational knowledge: Lessons from the leading edge. Employment Relations Today. 2003; 30(3): 51-63. http://dx.doi.org/10.1002/ert .10098
[55] Pulizzi J. The rise of storytelling as the new marketing. Publishing research quarterly. 2012; 28(2): 116-123. http://dx.doi.org/1 $0.1007 / \mathrm{s} 12109-012-9264-5$

[56] Lee Y, Shin W. Marketing tradition-bound products through storytelling: A case study of a Japanese sake brewery. Service Business. 2014; 1-15.

[57] Geiger D, Antonacopoulou E. Narratives and Organizational Dynamics: exploring blind spots and organizational inertia. Journal of Applied Behavioural Science. 2009; 45: 411-435. http: //dx.doi.org/10.1177/0021886309336402

[58] Whittle A, Mueller F, Mangan A. Storytelling and 'Character': Victims, Villans and Heroes in a Case of Technological Change. Organization. 2009; 16(3): 425-442. http://dx.doi.org/10.1177/1 350508409102305

[59] Beech N, MacPhail S, Coupland C. Anti-dialogic Positioning in Change Stories: Bank Robbers, Saviours and Peons. Organization. 2009; 16(3): 335-352. http://dx.doi.org/10.1177/1350508 409102299

[60] Tobin P. Once upon a time in Africa: a case study of storytelling for knowledge sharing. InAslib Proceedings: New Information Perspectives. 2008; 60(2): 130-142. http://dx.doi.org/10.1108/000 12530810862464

[61] Driver M. From Loss to Lack: Stories of Organizational Change as Encounters with Failed Fantasies of Self, Work and Organization. Organization. 2009; 16(3): 353-369. http://dx.doi.org/10.11 $77 / 1350508409102300$

[62] Rhodes C, Pullen A, Clegg SR. 'if i should fall from grace...': stories of change and organizational ethics. Journal of Business Ethics. 2010; 91: 535-551. http://dx.doi.org/10.1007/s10551-009-011 $6-\mathrm{y}$

[63] Connelly FM, Clandinin DJ. Stories of experience and narrative inquiry. Educational researcher. 1990; 19(5): 2-14. http://dx.doi . org/10.3102/0013189x019005002

[64] Gallagher KM. In search of a theoretical basis for storytelling in education research: Story as method. International Journal of Research \& Method in Education. 2011; 34(1): 49-61. http://dx.doi.org /10.1080/1743727X.2011.552308

[65] Skouge JR, Rao K. Digital Storytelling in Teacher Education: Creating Transformations through Narrative. Educational Perspectives. 2009; 42: 54-60.

[66] Gyabak K, Godina H. Digital storytelling in Bhutan: A qualitative examination of new media tools used to bridge the digital divide in a rural community school. Computers and Education. 2011; 57(4): 2236-2243. http://dx.doi.org/10.1016/j.compedu.2 011.06 .009

[67] Luwisch FE. Understanding what goes on in the heart and the mind: Learning about diversity and co-existence through storytelling. Teaching and teacher education. 2001; 17(2): 133-146. http://dx.doi.org/10.1016/S0742-051X (00)00047-0

[68] Suárez-Ortega M. Performance, reflexivity, and learning through biographical-narrative research. Qualitative Inquiry. 2013; 19(3): 189-200. http://dx.doi.org/10.1177/1077800412466223

[69] Rifa-Valls M. Experimenting with visual storytelling in students' portfolios: Narratives of visual pedagogy for pre-service teacher education. International Journal of Art \& Design Education. 2011; 30(2): 293. http://dx.doi.org/10.1111/j.1476-8070.2011 $.01674 . \mathrm{x}$

[70] Wijetunge P. Organizational storytelling as a method of tacitknowledge transfer: Case study from a Sri Lankan university. The International Information and Library Review. 2012; 44(4): 212-223. http://dx.doi.org/10.1016/j.iilr.2012.09.001 
[71] Baskerville D. Developing cohesion and building positive relationships through storytelling in a culturally diverse New Zealand classroom. Teaching and Teacher education. 2011; 27(1): 107-115. http://dx.doi.org/10.1016/j.tate.2010.07.007

[72] Breault RA. Distilling wisdom from practice: Finding meaning in PDS stories. Teaching and Teacher Education. 2010; 26(3): 399-407. http://dx.doi.org/10.1016/j.tate.2009.04.013

[73] Figueiredo R, Paiva A. In: "I Want to Slay That Dragon!"-Influencing Choice. in: Interactive Storytelling. In Interactive Storytelling. Springer Berlin Heidelberg. 2001; 26-37.

[74] Shank MJ. Teacher storytelling: A means for creating and learning within a collaborative space. Teaching and Teacher education. 2006; 22(6): 711-721. http://dx.doi.org/10.1016/j.tate. 2006.03 .002

[75] Rossiter MA. Narrative approach to development: Implications for adult education. Adult Education Quarterly. 1999; 50(1): 56-71. http://dx.doi.org/10.1177/07417139922086911

[76] Yang YTC, Chang CH. Empowering students through digital game authorship: Enhancing concentration, critical thinking, and academic achievement. Computers \& Education. 2013; 68: 334-344. http://dx.doi.org/10.1016/j.compedu.2013.05.023

[77] East L, Jackson D, O'Brien L. Disrupted relationships: adult daughters and father absence. Contemporary Nurse. 2006; 23(2): 252-261. PMid: 17343528. http://dx.doi.org/10.5172/conu. 2006. 2 3.2. 252

[78] Mannix J, Jackson D. Mothering and women's health: I love being a mother but... there is always something new to worry about. Australian Journal of Advanced Nursing. 2003; 20(3): 30.

[79] Block L, Leseho J. "Listen and I tell you something": Storytelling and social action in the healing of the oppressed. British Journal of Guidance \& Counselling. 2005; 33(2): 175-184. http: //dx.doi.org/10.1080/03069880500132706

[80] Colville I, Brown A, Pye A. Simplicity, Sense-making, organizing and storytelling for our time. Human Relations. 2012; 65: 5-15. http://dx.doi.org/10.1177/0018726711425617

[81] Dart J, Davies R. A Dialogical, Story-Based Evaluation Tool: The Most Significant Change. Evaluation Research Methods. 2005; 2(2): 37.

[82] Kitchen VLO. It Was Like a Fever: Storytelling in Protest and Politics (review). Social Forces. 2007; 85(4): 1825-1827.
[83] Baesler E, Bergoon J. The Temporal Effects of Story and Statistical Evidence on Belief Change. Communication Research. 1994; 21: v582-601. http://dx.doi.org/10.1177/00936509402100500 2

[84] Hyman D. Do Good Stories Make for Good Policy? Journal of Health Politics, Policy and Law. 2000; 25(6): 1150-1155. http: //dx.doi.org/10.1215/03616878-25-6-1149

[85] Grace PE. The effects of storytelling on worldview and attitudes toward sustainable agriculture. Doctoral dissertation, Virginia Polytechnic Institute and State University; 2011.

[86] Briggs RR. Storytelling for Social Justice: Connecting narrative and the arts in antiracist teaching. Equity \& Excellence in Education. 2011; 44(3): 445-449. http://dx.doi.org/10.1080/1066568 4.2011 .591675

[87] Ali MI. Stories/storytelling for women's empowerment/empowering stories. In Women's Studies International Forum. 2013; 45: 98-104. http://dx.doi.org/10.1016/j.wsif .2013.10.005

[88] Kincaid DL. Drama, emotion, and cultural convergence. Communication Theory. 2002; 12(2): 136-152. http://dx.doi.org/10.11 $11 / j .1468-2885.2002$.tb00263.x

[89] Yaphe J, Rigge M, Herxheimer A, et al. The use of patients' stories by self-help groups: a survey of voluntary organizations in the UK on the register of the College of Health. Health Expectations. 2000; 3(3): 176-181. PMid: 11281927. http://dx.doi.org/10.1046 /j.1369-6513.2000.00092.x

[90] Balen R, Rhodes C, Ward L. The power of stories: Using narrative for interdisciplinary learning in health and social care. Social Work Education. 2010; 29(4): 416-426. http://dx.doi.org/10.1080 /02615470902991742

[91] Divinsky M. Stories for life Introduction to narrative medicine. Canadian Family Physician. 2007; 53(2): 203-205. PMid: 17872627.

[92] Hansebo G, Kihlgren M. Patient life stories and current situation as told by carers in nursing home wards. Clinical Nursing Research. 2000; 9(3): 260-279. PMid: 11276619. http://dx.doi.org/10. $1177 / 10547730022158582$

[93] Hawkins J, Lindsay E. We listen but do we hear? The importance of patient stories. Wound Care. 2006; 11(9): S6-14. http: //dx.doi.org/10.12968/bjcn.2006.11.sup4.21767 